\title{
Osteopontin Gene Expression is Inversely Regulate 5-Fluorouracil Drug Resistance in Colon Cancer
}

\author{
Go Nakajima ${ }^{1,}$, , Kazuhiko Hayashi ${ }^{1}$, Masakazu Yamamoto ${ }^{2}$ \\ ${ }^{1}$ Department of Chemotherapy and Palliative Care, Tokyo Women's Medical University, Kawada-cho, Shinjuku-ku, Tokyo, Japan \\ ${ }^{2}$ Department of Surgery, Institute of Gastroenterology, Tokyo Women's Medical University, Kawada-cho, Shinjuku-ku, Tokyo, Japan
}

Emai address:

nakajima.go@twmu.ac.jp (G. Nakajima), hayashi.kazuhiko@twmu.ac.jp (K. Hayashi), yamamoto@ige.twmu.ac.jp (M. Yamamoto)

\section{To cite this article:}

Go Nakajima, Kazuhiko Hayashi, Masakazu Yamamoto. Osteopontin Gene Expression is Inversely Regulate 5-Fluorouracil Drug Resistance in Colon Cancer. Cancer Research Journal. Vol. 3, No. 2, 2015, pp. 42-46. doi: 10.11648/j.crj.20150302.13

\begin{abstract}
Background: Resistance to chemotherapeutic drugs complicates the treatment of cancer patients. The extracellular matrix protein osteopontin $(O P N)$ plays multiple roles in the proliferation and metastasis of cancer cells. We therefore attempted to determine whether $O P N$ expression correlated with drug resistance. Methods: $O P N$ expression in the HCT 116 colon cancer cell line was inhibited by an $O P N$-short interfering RNA (siRNA). We determined the cytotoxic effect $\left(\mathrm{IC}_{50}\right)$ of 5 -fluorouracil $(5 \mathrm{FU})$ on these cells. Patients with recurrence or colorectal cancer or harbored residual tumor cells were treated with S-1-based chemotherapy. The levels of $O P N$ mRNA expression in the tumors were determined and compared with the patients' responses to chemotherapy. Results: The $\mathrm{IC}_{50}$ of 5FU for HCT 116 cells transfected with the $O P N$-siRNA was $32.9 \mu \mathrm{M}$. In contrast, the $\mathrm{IC}_{50}$ values for cells transfected with a negative control siRNA, mock-transfected cells, or untreated cells were $6.58 \mu \mathrm{M}, 7.08 \mu \mathrm{M}$, and $6.76 \mu \mathrm{M}$, respectively $(\mathrm{P}<0.001)$. The level of $O P N$ mRNA expression in the $\mathrm{S}-1$ non-responder group was significantly lower than that of the responder group $(\mathrm{P}=0.0387)$. Survival analysis revealed no significant difference between the responder and non-responder groups $(\mathrm{P}=0.8737)$. Conclusions: The level of $O P N$ expression plays a role in the resistance of colorectal tumor cells to $5 \mathrm{FU}$.
\end{abstract}

Keywords: Osteopontin, Gene Expression, Colon Cancer, 5FU, Drug Resistance

\section{Introduction}

Colorectal cancer is the third and fourth leading cause of cancer-related deaths in Japan and worldwide[1, 2], respectively. Strategies for treating patients with colorectal cancer have changed markedly during this decade. Newly developed chemotherapeutic agents and combination treatment regimens have increased the overall survival of patients with unresectable colorectal cancer to more than 20 months[3]. For example, FOLFOX, FOLFIRI, CapeOX and SOX are used as first line chemotherapy for these patients[3-5]. Biotherapeutic monoclonal antibodies, including bevacizumab, cetuximab, and panitumumab are used in conjunction with these key regimens[6-8]. The metabolic antagonist $5 \mathrm{FU}$, in use as an anticancer drug for over 50 years[9], is common to all of these regimens and is widely used to treat a variety of cancers.

Diverse cell types express the extracellular matrix protein osteopontin $(O P N)$, including osteoblasts, osteoclasts, macrophages, activated $\mathrm{T}$ cells, and renal tubular cells $[10,11]$.
$O P N$ is widely expressed by tumor cells, such as those derived from the lung, breast, gastrointestinal tract, and ovary[12-15]. $O P N$ plays many important roles in apoptosis, bone regeneration, immune responses, and inflammation[16-18]. The binding of OPN to integrins and CD44 indicates that it participates in signaling pathways that promote the proliferation and metastasis of cancer cells $[19,20]$. Here we show, for the first time to our knowledge, that the level of transcription of $O P N$ in the colon cancer is strongly associated with resistance to $5 \mathrm{FU}$.

\section{Methods}

\subsection{Patients and Tissue Samples}

Twenty-nine patients who underwent surgery from 1996 to 2002 for colorectal tumor resection were including in the present study. If tumors recurred or residual tumor cells were detected, patients were enrolled in a clinical trial and treated with either S-1, 5FU-based oral therapy to improve efficacy and reduce side-effects, or S-1 plus cisplatin (CDDP). The 
dose of S-1 was determined based on the patient's body surface area (BSA) as follows: $<1.25 \mathrm{~m}^{2}, 80 \mathrm{mg} /$ day; $\geq 1.25$ and $<1.5 \mathrm{~m}^{2}, 100 \mathrm{mg} /$ day; and $>1.5 \mathrm{~m}^{2}, 120 \mathrm{mg} /$ day. The treatment regimens were as follows: S-1 alone was administered orally two times daily for 28 consecutive days and then discontinued for 2 weeks. S-1 was administered orally two times daily, discontinued for 2 weeks, and CDDP $\left(30 \mathrm{mg} / \mathrm{m}^{2}\right)$ was injected intravenously on days 1 and 8 .

The formalin-fixed paraffin-embedded (FFPE) specimens taken from colorectal tumors were obtained from the Department of Surgery, Institute of Gastroenterology, Tokyo Women's Medical University, Japan. Informed consent from all patients was obtained before administering chemotherapy or collecting tissues. FFPE tissues were prepared using the standard method of the Department of Pathology, Tokyo Women's Medical University, Japan. The paraffin blocks were cut into $10 \mu \mathrm{m}$-thick sections. The patients' characteristics are summarized in Table 1. Patients who responded completely (CR) or partially (PR) were assigned to the responder group (more than $30 \%$ tumor size shrinkage following chemotherapy), and patients with stable (SD) or progressive (PD) disease were assigned to the non-responder group.

\subsection{Cell Culture and Transfection with Small Interfering RNA (siRNA)}

The HCT 116 colorectal carcinoma cell line was obtained from the American Type Culture Collection (ATCC \#CCL-247TM, VA, USA) and maintained in McCoy's 5A medium supplemented with $10 \%$ heat-activated fetal bovine serum (FBS) (Life Technologies, NY, USA). The cells were incubated at $37^{\circ} \mathrm{C}$ in a humidified atmosphere containing $5 \%$ $\mathrm{CO}_{2}$. The cells were added to the wells of a 96-well plate and transfected with $5 \mathrm{nM}$ (final concentration) Silencer ${ }^{\circledR}$ Select siRNA (Life Technologies, NY, USA) targeting OPN mRNA $\left(O P N\right.$-siRNA cells) or with Silencer ${ }^{\circledR}$ Negative Control \#1 siRNA (NC\#1 cells) in Lipofectamine ${ }^{\circledR}$ RNAiMAX (Life Technologies, NY, USA) according to the manufacture's protocol. Other controls included cells treated with transfection reagent only (TA cells) and untreated cells (NTC cells).

\subsection{Cytotoxicity Assay}

The control and siRNA-transfected cells were incubated as described above for $24 \mathrm{~h}$ and washed twice with PBS. The cells were either untreated or exposed to 5FU (Sigma-Aldrich, MO, USA) in 10-fold increments of increasing amounts $(0-1000 \mu \mathrm{M}$, final concentration) and incubated for $48 \mathrm{~h}$. Cell counting was performed using WST-8 (Dojindo, Kumamoto, JAPAN) according to the manufacturer's protocol. In brief, WST- 8 was added to each well after removing the medium containing 5FU, incubated for $2 \mathrm{~h}$, after which the absorbance at $450 \mathrm{~nm}$ was measured using a microplate reader (Bio-Rad laboratories, CA, USA).

\subsection{RNA Isolation, cDNA Synthesis, and Real-time PCR}

Cells $\left(1 \times 10^{5}\right)$ in 6 -well plates were transfected with the
siRNAs described above according to the manufacture's protocol, incubated for $24 \mathrm{~h}$, and washed twice with PBS. TRIzol ${ }^{\circledR}$ reagent (Life Technologies, NY, USA) was added to each well, and total RNA was isolated according to the manufacture's protocol. For FFPE specimens, an RNeasy ${ }^{\circledR}$ FFPE Kit (QIAGEN, CA, USA) was used according to the manufacturer's protocol. Synthesis of complementary DNA (cDNA) was performed using a High Capacity cDNA Reverse Transcription Kit (Life Technologies, NY, USA) according to the manufacturer's protocol. The reverse transcription reaction was performed at $25^{\circ} \mathrm{C}$ for $10 \mathrm{~min}$ and then at $37^{\circ} \mathrm{C}$ for $120 \mathrm{~min}$. Quantitative real-time PCR was carried out using a StepOne ${ }^{\mathrm{TM}}$ Real-Time PCR System (Life Technologies, NY, USA). TaqMan ${ }^{\circledR}$ Gene Expression Assays (Life Technologies, NY, USA) were used according to the manufacturer's protocol as follows: $O P N$ (Assay ID: Hs00960942 m1) and GAPDH (Assay ID: Hs99999905_m1). PCR reactions were conducted as follows: $95^{\circ} \mathrm{C}$ for $3 \mathrm{~min}, 40$ cycles at $95^{\circ} \mathrm{C}$ for $15 \mathrm{~s}$, and $60^{\circ} \mathrm{C}$ for $35 \mathrm{~s}$.

\subsection{Data Analysis}

The threshold cycle $\left(\mathrm{C}_{\mathrm{T}}\right)$ value for each target was determined using StepOne ${ }^{\mathrm{TM}}$ software v.2.2 RQ Study Results (Applied Biosystems Inc.). The $2^{-\Delta \Delta \mathrm{Ct}}$ method was used to compare the levels of gene expression. The levels of expression of each mRNAs were normalized by calculating the delta- $\mathrm{C}_{\mathrm{T}}\left(\Delta \mathrm{C}_{\mathrm{T}}\right)$ values by subtracting the $\mathrm{C}_{\mathrm{T}}$ value of target mRNA from the $\mathrm{C}_{\mathrm{T}}$ value of the endogenous control GAPDH mRNA. The delta- $\Delta \mathrm{C}_{\mathrm{T}}\left(\Delta \Delta \mathrm{C}_{\mathrm{T}}\right)$ was calculated, and this value represents the difference in the $\Delta \mathrm{CT}$ value for each sample and the highest $\Delta \mathrm{CT}$ value as a calibrator. The $2^{-\Delta \Delta C t}$ value was used for relative quantitation. Statistical analyses were performed using MedCalc ${ }^{\circledR}$ for Windows, version 12.3.0.0 (MedCalc Software, Mariakerke, Belgium). ANOVA was used for assessing OPN-siRNA efficiency, and for calculating the differences of $\mathrm{IC}_{50}$. The statistical significance of differences between the level of expression of $O P N$ in the responder and non-responder groups was calculated using the Mann-Whitney test. The log-rank test for generating Kaplan-Meier survival curves was used to assess the association between the level of $O P N$ expression and the survival rate. Statistical significance was defined as $\mathrm{P} \leq 0.05$.

\section{Results}

\section{Cytotoxic effects of 5FU on HCT 116 cells}

The knock down efficiency for $O P N$ expression by $O P N$-siRNA was more than $99 \%(\mathrm{P}<0.001)$ (Figure 1 -A). The value of the $\mathrm{IC}_{50}$ of $5 \mathrm{FU}$ for $O P N$-siRNA cells was $32.9 \mu \mathrm{M}$. The $\mathrm{IC}_{50}$ values for cells transfected with a negative control siRNA, mock-transfected cells, and untreated cells were 6.58 $\mu \mathrm{M}, 7.08 \mu \mathrm{M}$, and $6.76 \mu \mathrm{M}$, respectively $(\mathrm{P}<0.001)$ (Figure 1-B).

The response of colorectal cancer patients to treatment with S-1 and analysis of their survival

The levels of $O P N$ mRNA expression were significantly lower in the non-responder group compared with those of the 
responder group $(\mathrm{P}=0.0387$ ) (Figure 2). There was no significant difference in the survival times between the responder and non-responder groups $(\mathrm{P}=0.8737)$ (Figure 3).

Table 1. Patient Characteristics.

\begin{tabular}{lll}
\hline Characteristics & Distribution & Percentage (\%) \\
\hline Age & & \\
mean (range) & $58.8(33-77)$ & \\
Gender & & \\
male & 16 & $55.2 \%$ \\
female & 13 & $44.8 \%$ \\
Primary site & & \\
cecum & 2 & $6.9 \%$ \\
ascending & 4 & $13.8 \%$ \\
transverse & 1 & $3.4 \%$ \\
descending & 2 & $6.9 \%$ \\
sigmoid & 11 & $37.9 \%$ \\
rectum & 9 & $31.0 \%$ \\
Histology & & \\
well & 18 & $62.1 \%$ \\
moderately & 8 & $27.6 \%$ \\
mucinous & 1 & $3.4 \%$ \\
well + mucinous & 1 & $3.4 \%$ \\
unknown & 1 & $3.4 \%$ \\
Treatment & & \\
S-1 alone & 18 & $62.1 \%$ \\
S-1 plus cisplatin & 11 & $37.9 \%$ \\
\hline
\end{tabular}

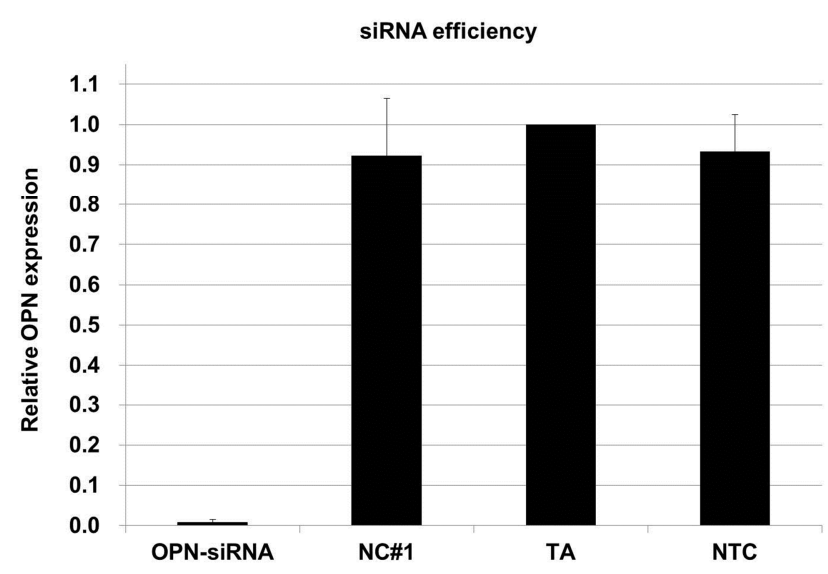

Figure 1-A. The knock down efficiency for OPN expression by OPN-siRNA was more than $99 \%(P<0.001)$.

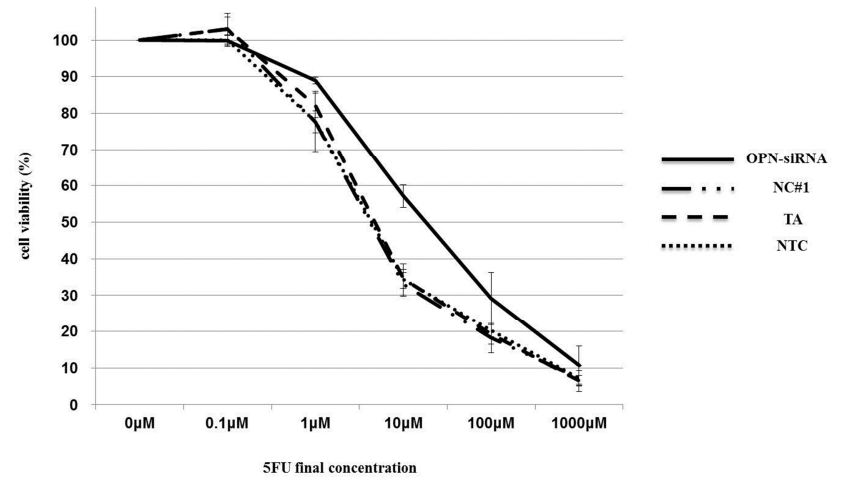

Figure 1-B. The value of the $I C_{50}$ of $5 F U$ for OPN-siRNA cells was $32.9 \mu \mathrm{M}$. The $I C_{50}$ values for cells transfected with a negative control siRNA, mock-transfected cells, and untreated cells were $6.58 \mu \mathrm{M}, 7.08 \mu \mathrm{M}$, and 6.76 $\mu M$, respectively $(P<0.001)$.

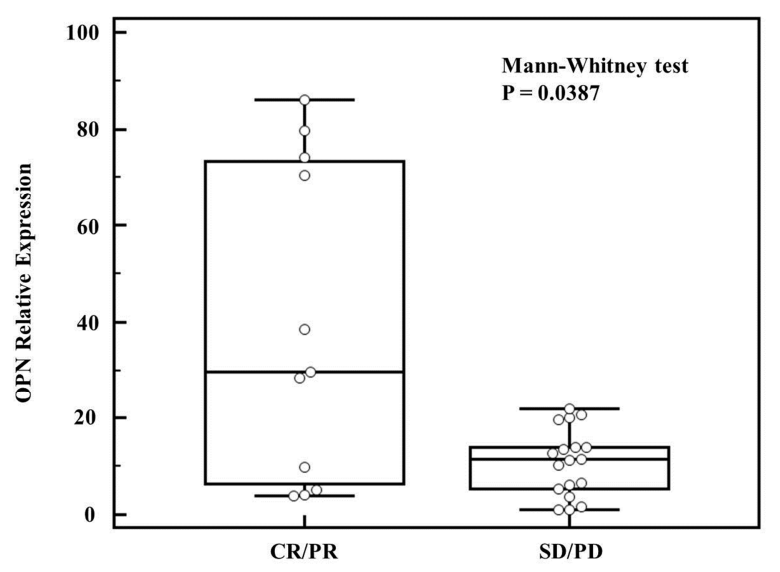

Figure 2. The levels of $O P N M R N A$ expression were significantly higher in the $S-1$ responder group compared with those of the non-responder group $(P=$ $0.0387)$.

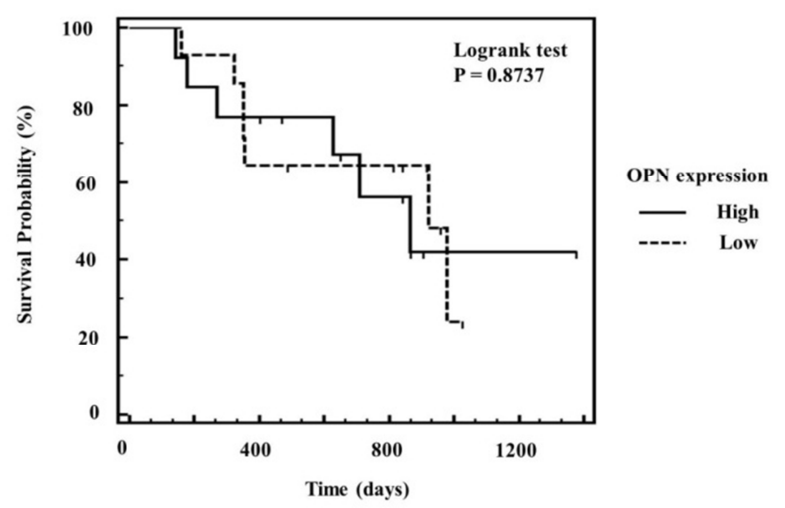

Figure 3. There was no significant difference in the overall survival times between the $S-1$ responder and non-responder groups $(P=0.8737)$.

\section{Discussion}

Numerous studies have failed to define the mechanism of resistance to $5 \mathrm{FU}$, although they have indicated that several factors may be involved. Nevertheless, they have contributed to the improvement of cancer treatment by revealing that cancer cells can acquire resistance to chemotherapy by expressing drug transporters, such as the $\mathrm{ABC}$ transporter that removes cytotoxic drugs from cells[21]. Other mechanisms of drug resistance include changes in drug metabolism, resistance to or inhibition of drug-induced apoptosis, damage to the DNA repair machinery, and overexpression of the proteins that promote the survival of tumor cells[22, 23].

The details of the mechanisms by which cells metabolize $5 \mathrm{FU}$ have been revealed by research conducted over many years. When 5FU is incorporated by tumor cells, most of it is degraded by dihydropyrimidine dehydrogenase (DPD). Undegraded $5 \mathrm{FU}$ is phosphorylated, and the product, 5-fluoro-deoxyuridine monophosphate (FdUMP), prevents de novo DNA synthesis by forming complexes with thymidylate synthase (TS) with folate as a co-factor[24]. The expression by tumors of higher than normal levels of TS or DPD results in shorter survival of patients[25].

$O P N$ forms complexes with integrins and $C D 44[19,20]$, 
which promote the proliferation, migration, and metastases of tumor cells[26-28]. Furthermore, its level of expression reflects the malignant potential of a tumor[29]. We show here that a human colorectal cell line acquires resistance to $5 \mathrm{FU}$ when $O P N$ mRNA expression is reduced by an $O P N$-specific siRNA. Because the expression of $O P N$ accelerates the proliferation of tumor cells[26], inhibiting its expression reduces the rates of DNA synthesis and cell proliferation. Further studies will be required to determine the pathways through which $O P N$ influences the response of tumor cells to $5 \mathrm{FU}$.

The sensitivity of HCT 116 cells to $5 \mathrm{FU}$ as a function of $O P N$ mRNA expression is reflected by our analysis of $O P N$ expression in patients that did or did not respond to therapy with 5FU. Interestingly, the levels of $O P N$ expression in tumors derived from the non-responder group were significantly lower compared with those of the responder group. This result is consistent with the aforementioned results of the siRNA experiments. However, the survival times of the responder and non-responder groups were not significantly different. Currently, several drugs are used sequentially to treat colon cancer, and the survival data reported here may reflect treatment with a single drug. This result suggests possibilities for developing new therapeutic strategies development or new agents, and may help elucidate the mechanism of resistance to $5 \mathrm{FU}$.

In conclusion, we demonstrate that a colon cancer cell line becomes more resistant to the cytotoxic effects of 5FU when $O P N$ expression is inhibited. These findings are consistent with the low levels of $O P N$ expression in patients with colon cancer that responded poorly to $5 \mathrm{FU}$ based chemotherapy.

\section{Acknowledgement}

We are very grateful to M. Hirokawa, K. Ohsuga, S. Okamoto, and A. Nakamura for their valuable assistance.

\section{References}

[1] T. Matsuda, T. Marugame, K. Kamo, K. Katanoda, W. Ajiki, T. Sobue, et al., "Cancer incidence and incidence rates in Japan in 2002: based on data from 11 population-based cancer registries," Jpn J Clin Oncol, vol. 38, pp. 641-8, Sep 2008.

[2] J. Ferlay, H. R. Shin, F. Bray, D. Forman, C. Mathers, and D. M Parkin, "Estimates of worldwide burden of cancer in 2008: GLOBOCAN 2008," Int J Cancer, vol. 127, pp. 2893-917, Dec 2010.

[3] C. Tournigand, T. André, E. Achille, G. Lledo, M. Flesh, D. Mery-Mignard, et al., "FOLFIRI followed by FOLFOX6 or the reverse sequence in advanced colorectal cancer: a randomized GERCOR study," J Clin Oncol, vol. 22, pp. 229-37, Jan 2004.

[4] J. Cassidy, S. Clarke, E. Díaz-Rubio, W. Scheithauer, A. Figer, R. Wong, et al., "Randomized phase III study of capecitabine plus oxaliplatin compared with fluorouracil/folinic acid plus oxaliplatin as first-line therapy for metastatic colorectal cancer," J Clin Oncol, vol. 26, pp. 2006-12, Apr 2008.
[5] Y. Yamada, D. Takahari, H. Matsumoto, H. Baba, M. Nakamura, K. Yoshida, et al., "Leucovorin, fluorouracil, and oxaliplatin plus bevacizumab versus S-1 and oxaliplatin plus bevacizumab in patients with metastatic colorectal cancer (SOFT): an open-label, non-inferiority, randomised phase 3 trial," Lancet Oncol, vol. 14, pp. 1278-86, Dec 2013.

[6] H. S. Hochster, L. L. Hart, R. K. Ramanathan, B. H. Childs, J. D. Hainsworth, A. L. Cohn, et al., "Safety and efficacy of oxaliplatin and fluoropyrimidine regimens with or without bevacizumab as first-line treatment of metastatic colorectal cancer: results of the TREE Study," J Clin Oncol, vol. 26, pp. 3523-9, Jul 2008.

[7] H. Hurwitz, L. Fehrenbacher, W. Novotny, T. Cartwright, J. Hainsworth, W. Heim, et al., "Bevacizumab plus irinotecan, fluorouracil, and leucovorin for metastatic colorectal cancer," N Engl J Med, vol. 350, pp. 2335-42, Jun 2004.

[8] D. Cunningham, Y. Humblet, S. Siena, D. Khayat, H. Bleiberg, A. Santoro, et al., "Cetuximab monotherapy and cetuximab plus irinotecan in irinotecan-refractory metastatic colorectal cancer," N Engl J Med, vol. 351, pp. 337-45, Jul 2004.

[9] C. HEIDELBERGER, N. K. CHAUDHURI, P. DANNEBERG D. MOOREN, L. GRIESBACH, R. DUSCHINSKY, et al., "Fluorinated pyrimidines, a new class of tumour-inhibitory compounds," Nature, vol. 179, pp. 663-6, Mar 1957.

[10] H. Okada, K. Moriwaki, R. Kalluri, T. Takenaka, H. Imai, S. Ban, et al., "Osteopontin expressed by renal tubular epithelium mediates interstitial monocyte infiltration in rats," Am J Physiol Renal Physiol, vol. 278, pp. F110-21, Jan 2000.

[11] M. Mazzali, T. Kipari, V. Ophascharoensuk, J. A. Wesson, R. Johnson, and J. Hughes, "Osteopontin--a molecule for all seasons," QJM, vol. 95, pp. 3-13, Jan 2002.

[12] J. Zhang, K. Takahashi, F. Takahashi, K. Shimizu, F. Ohshita, Y. Kameda, et al., "Differential osteopontin expression in lung cancer," Cancer Lett, vol. 171, pp. 215-22, Oct 2001.

[13] A. B. Tuck and A. F. Chambers, "The role of osteopontin in breast cancer: clinical and experimental studies," J Mammary Gland Biol Neoplasia, vol. 6, pp. 419-29, Oct 2001.

[14] D. X. Cao, Z. J. Li, X. O. Jiang, Y. L. Lum, E. Khin, N. P. Lee, et al., "Osteopontin as potential biomarker and therapeutic target in gastric and liver cancers," World J Gastroenterol, vol. 18, pp. 3923-30, Aug 2012.

[15] K. A. Brakora, H. Lee, R. Yusuf, L. Sullivan, A. Harris, T. Colella, et al., "Utility of osteopontin as a biomarker in recurrent epithelial ovarian cancer," Gynecol Oncol, vol. 93, pp. 361-5, May 2004.

[16] G. F. Weber, "The metastasis gene osteopontin: a candidate target for cancer therapy," Biochim Biophys Acta, vol. 1552, pp. 61-85, Dec 2001.

[17] M. K. El-Tanani, "Role of osteopontin in cellular signaling and metastatic phenotype," Front Biosci, vol. 13, pp. 4276-84, 2008.

[18] H. Rangaswami, A. Bulbule, and G. C. Kundu, "Osteopontin: role in cell signaling and cancer progression," Trends Cell Biol, vol. 16, pp. 79-87, Feb 2006.

[19] A. Bellahcène, V. Castronovo, K. U. Ogbureke, L. W. Fisher, and N. S. Fedarko, "Small integrin-binding ligand N-linked glycoproteins (SIBLINGs): multifunctional proteins in cancer," Nat Rev Cancer, vol. 8, pp. 212-26, Mar 2008. 
[20] J. L. Lee, M. J. Wang, P. R. Sudhir, G. D. Chen, C. W. Chi, and J. Y. Chen, "Osteopontin promotes integrin activation through outside-in and inside-out mechanisms: OPN-CD44V interaction enhances survival in gastrointestinal cancer cells," Cancer Res, vol. 67, pp. 2089-97, Mar 2007.

[21] Z. S. Chen and A. K. Tiwari, "Multidrug resistance proteins (MRPs/ABCCs) in cancer chemotherapy and genetic diseases," FEBS J, vol. 278, pp. 3226-45, Sep 2011.

[22] M. M. Gottesman, "Mechanisms of cancer drug resistance," Annu Rev Med, vol. 53, pp. 615-27, 2002.

[23] M. R. Lackner, T. R. Wilson, and J. Settleman, "Mechanisms of acquired resistance to targeted cancer therapies," Future Oncol, vol. 8, pp. 999-1014, Aug 2012.

[24] D. B. Longley, D. P. Harkin, and P. G. Johnston, "5-fluorouracil: mechanisms of action and clinical strategies," Nat Rev Cancer, vol. 3, pp. 330-8, May 2003.
[25] D. Salonga, K. D. Danenberg, M. Johnson, R. Metzger, S. Groshen, D. D. Tsao-Wei, et al., "Colorectal tumors responding to 5-fluorouracil have low gene expression levels of dihydropyrimidine dehydrogenase, thymidylate synthase, and thymidine phosphorylase," Clin Cancer Res, vol. 6, pp. 1322-7, Apr 2000.

[26] A. Angelucci, C. Festuccia, G. L. Gravina, P. Muzi, L. Bonghi, C. Vicentini, et al., "Osteopontin enhances the cell proliferation induced by the epidermal growth factor in human prostate cancer cells," Prostate, vol. 59, pp. 157-66, May 2004.

[27] T. Standal, M. Borset, and A. Sundan, "Role of osteopontin in adhesion, migration, cell survival and bone remodeling," Exp Oncol, vol. 26, pp. 179-84, Sep 2004.

[28] P. Y. Wai and P. C. Kuo, "Osteopontin: regulation in tumor metastasis," Cancer Metastasis Rev, vol. 27, pp. 103-18, Mar 2008.

[29] G. F. Weber, G. S. Lett, and N. C. Haubein, "Osteopontin is a marker for cancer aggressiveness and patient survival," $\mathrm{Br} J$ Cancer, vol. 103, pp. 861-9, Sep 2010. 